OPEN ACCESS

Edited by:

Seana Gall,

University of Tasmania, Australia

Reviewed by:

Sabah Rehman,

University of Tasmania, Australia

Hoang T. Phan,

University of Tasmania, Australia

*Correspondence:

Lihui Zhang

zhanglihui10510@163.com

Specialty section:

This article was submitted to

Cardiovascular Epidemiology

and Prevention

a section of the journal

Frontiers in Cardiovascular Medicine

Received: 25 April 2021

Accepted: 09 February 2022

Published: 07 March 2022

Citation:

Hao Z, Wang M, Zhu Q, Li J,

Liu Z, Yuan L, Zhang Y and Zhang L

(2022) Association Between

Socioeconomic Status

and Prevalence of Cardio-Metabolic Risk Factors: A Cross-Sectional Study

on Residents in North China.

Front. Cardiovasc. Med. 9:698895.

doi: $10.3389 / f c v m .2022 .698895$

\section{Association Between Socioeconomic Status and Prevalence of Cardio-Metabolic Risk Factors: A Cross-Sectional Study on Residents in North China}

\author{
Zhihua Hao, Mian Wang, Qiuxiao Zhu, Jie Li, Zibo Liu, Lingling Yuan, Yue Zhang and \\ Lihui Zhang*
}

Department of Endocrinology, Second Hospital of Hebei Medical University, Shijiazhuang, China

Studies have found associations between cardio-metabolic disorders and socioeconomic status (SES) in developed areas. However, little epidemiological data are available on residents of less developed areas in North China. A crosssectional study that consisted of 2,650 adults randomly selected from local residents was conducted on a developing province, Hebei. SES was assessed in terms of education, personal income per year, and occupation. The association between SES and metabolic syndrome (MetS) was determined by multivariate logistic regression. The weighted prevalence of MetS was $26.8 \%$ among residents of Hebei province. The lower prevalence of MetS and abdominal obesity was associated with increase in SES groups. After adjustments regarding age, sex, body mass index, living area, smoking, salt intake, and family history of diabetes, odds ratio (OR) for elevated blood pressure (BP) of individuals with higher SES level was 0.71 [95\% confidence interval (Cl): 0.542-0.921] compared with those with lower SES level. Cardio-metabolic risk factors were commonly identified among residents of Hebei province in north China and were associated with SES conditions. This study indicated that from a public health perspective, more attention should be paid to screening of cardio-metabolic disorders in less developed areas.

Keywords: socioeconomic status, cardio-metabolic risk factors, metabolic syndrome, public health, epidemiology

\section{INTRODUCTION}

Cardiovascular and metabolic diseases are leading causes of death and pose a great threat to public health, especially in developing countries (1-3). Metabolic syndrome (MetS) is a set of physiological and biochemical disorders that are characterized by pathological components such as abdominal obesity, impaired glucose metabolism, and increased blood pressure. It has been known that the occurrence of MetS is associated with increased risks of developing cardio-metabolic diseases such as diabetes, hypertension, coronary heart disease, and stroke (4). The prevalence of cardiometabolic disorders is on the rise among Chinese populations and has already become the primary cause of death among Chinese residents (5). 
Metabolic syndrome and its components are closely associated with increased risks of cardio-metabolic disorders $(6,7)$. Other cardio-metabolic risk factors include gender, lifestyle, family history of disease, and socioeconomic status (SES) (8). SES reflects a person's position in society and mainly includes education, income, and occupation. Previous studies have demonstrated that lower SES was associated with higher risk of cardio-metabolic disorders in developed countries $(9,10)$. China has experienced great social and economic transitions in the last decades. These transitions accompany lifestyle changes such as abundance in high-calorie foods and decrease in physical work, and have led to sharp increase in cardio-metabolic diseases (11). Several studies have investigated the association between SES and prevalence of cardio-metabolic risk factors in China. However, most of these studies were carried out on developed areas (12, 13), and only few have been reported on populations in less developed areas. Hebei is a developing province located in the North China Plain and surrounded by the capital Beijing. This is the first time the association between SES and prevalence of cardio-metabolic risk factors among residents of Hebei province has been investigated.

\section{MATERIALS AND METHODS}

\section{Study Population}

This epidemiological study was implemented in September 2016 and conducted in Hebei province. Sample selection was conducted based on a multistage, stratified sampling method. First, cities of Shijiazhuang and Renqiu were selected as representative urban and rural areas of Hebei province based on gross domestic product per capita. Second, one district was randomly selected from each city. Next, several residential communities were randomly selected from each district, and eligible individuals who met the inclusion criteria were included. The composition of age and sex of each community and urbanrural ratio are designed based on latest national census data (14) and are presented in Supplementary Table 1.

The inclusion criteria were as follows: age 18 years or older, has lived in the selected community for at least 5 years, and not pregnant. A total of 2,650 adults were randomly selected from local residents. Our study eventually included 2,638 participants after excluding 12 people with missing information on sex, age, plasma glucose, or SES questionnaire. This study was approved by the Medical Ethics Committee of The Second Hospital of Hebei Medical University, and all methods were performed in accordance with relevant guidelines and regulations. All participants provided written informed consent following a thorough explanation of research procedures. A flow diagram of the analytical sample is presented in Supplementary Figure 1.

\section{Clinical and Laboratory Measurements}

A standardized questionnaire was administered by trained professionals to collect in regional locations. Body weight, height, waist circumference, and BP were measured by trained nurses according to standard protocols. Body mass index (BMI) was calculated as weight $(\mathrm{kg}) /$ height $\left(\mathrm{m}^{2}\right)$ and was classified into three categories: normal $\left(<24 \mathrm{~kg} / \mathrm{m}^{2}\right)$, overweight $(\geq 24$ and $\left.<28 \mathrm{~kg} / \mathrm{m}^{2}\right)$, and obese $\left(\geq 28 \mathrm{~kg} / \mathrm{m}^{2}\right)$ according to the criteria (15). Waist circumference (WC) was measured midway between the lower border of the rib margin and the iliac crest at the end of normal expiration. Salt intake was classified into three categories: mild ( $<5 \mathrm{~g} /$ day), moderate (5-10 g/day), and severe (>10 g/day). Systolic blood pressure (SBP) and diastolic blood pressure (DBP) were measured with an electronic blood pressure monitor (Omron HEM-7430; Omron Corporation, Kyoto, Japan) on the non-dominant arm twice according to standard protocols.

After $12 \mathrm{~h}$ of overnight fasting, a blood sample was drawn from each participant, and fasting blood glucose (FBG), total cholesterol (TC), triglycerides (TGs), high-density lipoprotein cholesterol (HDL-C), and low-density lipoprotein cholesterol (LDL-C) were measured using an automatic biochemical analyzer (Mindray BS-180 Analyzer) according to standard protocols.

\section{Clinical Assessments \\ Cardio-Metabolic Risk Factors}

The participants were diagnosed with MetS if they had at least three of the following criteria according to Chinese Diabetes Society-2017 (CDS-2017) (15): (1) abdominal obesity: $\mathrm{WC} \geq 90 \mathrm{~cm}$ for males and $\mathrm{WC} \geq 85 \mathrm{~cm}$ for females; (2) elevated blood glucose (BG): $\geq 6.1 \mathrm{mmol} / \mathrm{L}$ or $2 \mathrm{~h}$ OGTT $\geq 7.8 \mathrm{mmol} / \mathrm{L}$ and (or) diabetes history; (3) elevated blood pressure (BP): $\geq 130 / 85 \mathrm{mmHg}$ and (or) self-reported hypertension history; (4) elevated TG: $\geq 1.7 \mathrm{mmol} / \mathrm{L}$; (5) Low HDL-C: $<1.04 \mathrm{mmol} / \mathrm{L}$.

\section{Socioeconomic Status Assessment}

In order to evaluate SES, variables were calculated using a score of 1-5. A socioeconomic score for a participant was the sum of the following three variables: education: (1) no formal education, (2) elementary school education, (3) junior middle school education, (4) senior high school education, and (5) university education and above; occupation: (1) no stable work, (2) labor work, (3) clerical work, (4) graduate/technician work, and (5) management positions; individual income per year: (1) less than 10,000 yuan, (2) 10,000-30,000 yuan, (3) 30,000-50,000 yuan, (4) 50,000100,000 yuan, and (5) more than 100,000 yuan.

The composite score was calculated for every participant in SES dimension. The lowest composite score is 3 points and the highest is 15 points. The distribution of SES scores was spilt into tertiles where $\mathrm{T} 1$ was the reference group and T3 was the best.

\section{Statistical Analysis}

To account for the complex sampling design of this study, we used the SUDAAN software (Research Triangle Institute, North Carolina, United States) to obtain estimates of prevalence and standard errors according to the Taylor linearization method. Estimates were weighted to reflect age, sex, and urban-rural distribution of adults living in Hebei province. Weighting coefficients were derived from the 2010 Chinese population census data, and the sampling scheme of our survey was designed to obtain a representative estimate. Categorical 
TABLE 1 | Baseline characteristics of the study by demographic data and clinical variables.

\begin{tabular}{|c|c|c|c|c|}
\hline Characteristics & $\begin{array}{c}\text { Total } \\
(n=2,638)\end{array}$ & $\begin{array}{c}\text { MetS } \\
(n=716)\end{array}$ & $\begin{array}{l}\text { Non-MetS } \\
(n=1,922)\end{array}$ & $P$-value \\
\hline Gender, $n(\%)$ & & & & $<0.01$ \\
\hline Male & 1352 (51.3) & $479(35.4)$ & $873(64.6)$ & \\
\hline Female & $1286(48.7)$ & $237(18.4)$ & 1049 (81.6) & \\
\hline Location, $n(\%)$ & & & & 0.05 \\
\hline Urban area & $1389(52.7)$ & $399(28.7)$ & $990(71.3)$ & \\
\hline Rural area & 1249 (47.3) & $317(25.4)$ & $932(74.6)$ & \\
\hline Age groups, $n(\%)$ & & & & $<0.01$ \\
\hline $18-29$ & $673(25.5)$ & $67(10.0)$ & $606(90.0)$ & \\
\hline 30-39 & $542(20.5)$ & $132(24.4)$ & $410(75.6)$ & \\
\hline $40-49$ & $576(21.8)$ & $144(25.0)$ & $432(75.0)$ & \\
\hline $50-59$ & $405(15.4)$ & $175(43.2)$ & $230(56.8)$ & \\
\hline $60-69$ & $248(9.4)$ & $108(43.5)$ & $140(56.5)$ & \\
\hline $70-$ & $194(7.4)$ & $90(46.4)$ & $104(53.6)$ & \\
\hline Smoking, $n(\%)$ & & & & $<0.01$ \\
\hline No & $1918(72.7)$ & $452(23.6)$ & $1466(76.4)$ & \\
\hline Yes & $720(27.3)$ & $264(36.7)$ & $456(63.3)$ & \\
\hline Salt intake, $n(\%)$ & & & & $<0.01$ \\
\hline Mild & $420(15.9)$ & $96(22.9)$ & $324(77.1)$ & \\
\hline Moderate & 1799 (68.2) & $471(26.2)$ & $1328(73.8)$ & \\
\hline Heavy & 419 (15.9) & $149(35.6)$ & $270(64.4)$ & \\
\hline Family history of diabetes, $n(\%)$ & & & & 0.17 \\
\hline No & $2,042(77.4)$ & $541(26.5)$ & $1,501(73.5)$ & \\
\hline Yes & $596(22.6)$ & $175(29.4)$ & $421(70.6)$ & \\
\hline BMI, $n(\%)$ & & & & $<0.01$ \\
\hline Normal & 1,052 (39.9) & $68(64.6)$ & $984(35.4)$ & \\
\hline Overweight & $981(37.2)$ & $288(29.4)$ & $693(70.6)$ & \\
\hline Obesity & $605(22.9)$ & $360(59.5)$ & $245(40.5)$ & \\
\hline \multicolumn{5}{|l|}{ Individual-level SES variables } \\
\hline Education, $n(\%)$ & & & & $<0.01$ \\
\hline No formal education & $138(5.2)$ & $57(41.3)$ & $81(58.7)$ & \\
\hline Elementary school education & $228(8.6)$ & $105(46.1)$ & $123(53.9)$ & \\
\hline Junior middle school education & $678(25.7)$ & $212(31.3)$ & $466(68.7)$ & \\
\hline Senior high school education & 789 (29.9) & $176(22.3)$ & $613(77.7)$ & \\
\hline University education and above & $805(30.5)$ & $166(20.6)$ & $639(79.4)$ & \\
\hline Family income per year, $n(\%)$ & & & & 0.33 \\
\hline Less than $10,000 \mathrm{CNY}$ & $651(24.7)$ & $188(28.9)$ & $463(71.1)$ & \\
\hline 10,000-30,000 CNY & $474(18.0)$ & $120(25.3)$ & $354(74.7)$ & \\
\hline 30,000-50,000 CNY & $726(27.5)$ & $199(27.4)$ & $527(72.6)$ & \\
\hline 50,000-100,000 CNY & $620(23.5)$ & $173(27.9)$ & $447(72.1)$ & \\
\hline More than $100,000 \mathrm{CNY}$ & $167(6.3)$ & $36(21.6)$ & $131(78.4)$ & \\
\hline Occupation, $n(\%)$ & & & & $<0.01$ \\
\hline No stable work & $895(33.9)$ & $215(24.0)$ & $680(76.0)$ & \\
\hline Labor work & 1204 (45.6) & $378(31.4)$ & 826 (68.6) & \\
\hline Clerical work & $487(18.5)$ & $111(22.8)$ & $376(77.2)$ & \\
\hline Graduate/technician work & $47(1.8)$ & $10(21.3)$ & $37(78.7)$ & \\
\hline Management positions & $5(0.2)$ & $2(40.0)$ & $3(60.0)$ & \\
\hline SES groups, $n(\%)$ & & & & $<0.01$ \\
\hline $\mathrm{T} 1$ & $818(31.0)$ & 269 (32.9) & $549(67.1)$ & \\
\hline $\mathrm{T} 2$ & $946(35.9)$ & $240(25.4)$ & 706 (74.6) & \\
\hline T3 & $874(33.1)$ & $207(23.7)$ & 667 (76.3) & \\
\hline
\end{tabular}


TABLE 1 | (Continued)

\begin{tabular}{|c|c|c|c|c|}
\hline Characteristics & $\begin{array}{c}\text { Total } \\
(n=2,638)\end{array}$ & $\begin{array}{c}\text { MetS } \\
(n=716)\end{array}$ & $\begin{array}{l}\text { Non-MetS } \\
(n=1,922)\end{array}$ & $P$-value \\
\hline \multicolumn{5}{|c|}{ Clinical variables, mean \pm SD } \\
\hline $\mathrm{BMI}, \mathrm{kg} / \mathrm{m}^{2}$ & $25.15 \pm 4.02$ & $28.21 \pm 3.46$ & $24.01 \pm 3.60$ & $<0.01$ \\
\hline WC, $\mathrm{cm}$ & $85.03 \pm 11.20$ & $94.91 \pm 8.00$ & $81.35 \pm 9.93$ & $<0.01$ \\
\hline $\mathrm{SBP}, \mathrm{mmHg}$ & $127.30 \pm 19.50$ & $140.84 \pm 18.26$ & $122.25 \pm 17.43$ & $<0.01$ \\
\hline $\mathrm{FBG}, \mathrm{mmol} / \mathrm{L}$ & $5.62 \pm 1.50$ & $6.47 \pm 2.19$ & $5.31 \pm 0.96$ & $<0.01$ \\
\hline $\mathrm{TG}, \mathrm{mmol} / \mathrm{L}$ & $1.63 \pm 1.48$ & $2.67 \pm 2.12$ & $1.24 \pm 0.88$ & $<0.01$ \\
\hline $\mathrm{TC}, \mathrm{mmol} / \mathrm{L}$ & $4.63 \pm 1.10$ & $5.07 \pm 1.08$ & $4.46 \pm 1.06$ & $<0.01$ \\
\hline $\mathrm{HDL}-\mathrm{C}, \mathrm{mmol} / \mathrm{L}$ & $1.39 \pm 0.37$ & $1.17 \pm 0.31$ & $1.47 \pm 0.36$ & $<0.01$ \\
\hline LDL-C, mmol/L & $2.63 \pm 0.79$ & $2.95 \pm 0.80$ & $2.52 \pm 0.75$ & $<0.01$ \\
\hline
\end{tabular}

MetS, metabolic syndrome; BMI, body mass index; SES, socioeconomic status; T, tertile; WC, waist circumference; SBP, systolic blood pressure; DBP, diastolic blood pressure; FBG, fasting blood glucose; TG, triglycerides; TC, total cholesterol; HDL-C, high density lipoprotein-cholesterol; LDL-C, low density lipoprotein-cholesterol; CNY, Chinese Yuan.

data presented as counts and percentages were analyzed by chi-square test or Fisher's exact test, as appropriate. The POLYNOMIAL statement was used to assess significant linear trend and quadratic trend for the levels of an ordinal group. The normality of continuous variables was assessed, and variables with skewed distribution were reported with medians and interquartile ranges (IQRs); otherwise, continuous data are presented as means and standard deviations. Adjusted odds ratios (ORs) with 95\% CIs were calculated by multivariable logistic regression to examine the association between independent variables with MetS and its components. Three models with progressively increased adjustment of risk factors among all the participants were applied for sensitive analysis (Supplementary Tables 2, 3). All statistical analyses were conducted using Statistical Analysis System version 9.3 (SAS Institute, Inc., North Carolina, NC, United States) and SUDAAN software version 10.0. A $p$-value of $<0.05$ was considered statistically significant.

\section{RESULTS}

\section{Basic Characteristics of the Study Population}

Overall, 2,638 adults out of 2,650 invited local residents completed the questionnaire for this cross-sectional study, and $716(27.1 \%)$ was diagnosed with MetS (Table 1). The prevalence of MetS was significantly higher in males (35.4\%) than in females $(18.4 \%)(p<0.01)$. The prevalence of MetS increased with increase in age groups (Table 1). More than $90 \%$ of participants diagnosed with MetS were overweight or obese. People with MetS had significantly increased prevalence of smoking and heavy salt intake, and their SES conditions were also different compared with those with no MetS (all $p<0.05$ ). There were significantly more under-educated (below senior high school) participants in the MetS (52.3\%) group compared to the non-MetS (34.9\%) group. Interestingly, we did not observe any difference in family income between participants in the MetS and non-MetS groups $(p=0.33)$.

Compared with those with no MetS, participants with MetS reported significantly higher levels of age, BMI, and WC, and higher values of SBP, DBP, FBG, TG, TC, and LDL-C, and lower values of HDL-C (all $p<0.01$ ). Meanwhile, we found no significant differences in terms of location and family history of diabetes in the MetS and non-MetS groups $(p>0.05)$.

\section{Weighted Prevalence of MetS and Its Components Across Groups of SES}

The most common cardio-metabolic risk factors were elevated BP (46.2\%), abdominal obesity (42.9\%), elevated TG (31.2\%), elevated BG (23.4\%), and low HDL-C (14.9\%). As shown in Table 2, the weighted prevalence of MetS (26.8\%) and its components were different under three SES conditions. In general, a negative linear association was found between prevalence of MetS and abdominal obesity with increase in SES groups.

\section{Adjusted ORs for MetS and Its Components Among Different Risk Factors}

Multivariate logistic regression analysis suggested that the associations between SES levels and MetS were not statistically significant. Participants with higher SES condition (T3) had a significantly lower risk of having elevated BP (OR:0.71, 95\% CI:0.54-0.92) than those with lower SES (T1). The analysis also suggested that age was an important risk factor for MetS and its components, with ORs appearing an increasing trend with increase in age, except for elevated TG and low HDLC. In addition, the ORs of MetS (OR:0.48; 95\% CI:0.37-0.61), abdominal obesity (OR:0.43; 95\% CI:0.34-0.56), elevated BG (OR:0.78; 95\% CI:0.62-0.99), elevated BP (OR:0.46; 95\% CI:0.370.57 ), elevated TG (OR:0.76; 95\% CI:0.61-0.94), and low HDLC (OR:0.38; 95\% CI:0.28-0.51) were significantly decreased in females than males. The ORs of MetS and its components 
TABLE 2 | Weighted prevalence of MetS and its components across groups of SES.

\begin{tabular}{|c|c|c|c|c|c|c|c|}
\hline \multirow[t]{2}{*}{ Diagnosis, $n$ (\%) } & \multicolumn{4}{|c|}{ SES groups } & \multirow[t]{2}{*}{$P$ for difference } & \multirow[t]{2}{*}{$P$ for linear trend } & \multirow[t]{2}{*}{$P$ for quadratic trend } \\
\hline & T1 $(n=818)$ & T2 $(n=946)$ & T3 $(n=874)$ & Total $(n=2,638)$ & & & \\
\hline MetS & 269 (33.7\%) & 240 (25.1\%) & 207 (22.2\%) & 716 (26.8\%) & 0.01 & 0.01 & 0.65 \\
\hline Abdominal obesity & 405 (53.6\%) & 392 (41.9\%) & 309 (34.2\%) & 1106 (42.9\%) & 0.04 & 0.04 & 0.79 \\
\hline Elevated BG & 269 (33.2\%) & 204 (20.5\%) & 171 (17.4\%) & 644 (23.4\%) & 0.13 & 0.09 & 0.38 \\
\hline Elevated BP & 472 (59.3\%) & 424 (46.4\%) & 308 (33.8\%) & 1204 (46.2\%) & 0.11 & 0.14 & 0.99 \\
\hline Elevated TG & $240(28.9 \%)$ & 308 (32.0\%) & 308 (32.4\%) & 856 (31.2\%) & 0.08 & 0.38 & 0.44 \\
\hline Low HDL-C & 110 (14.7\%) & 131 (13.6\%) & 144 (16.5\%) & 385 (14.9\%) & 0.66 & 0.27 & 0.21 \\
\hline
\end{tabular}

T, tertile; MetS, metabolic syndrome; BG, blood glucose; BP, blood pressure; TG, triglycerides; HDL-C, high density lipoprotein-cholesterol.

TABLE 3 | Associations of independent variables with MetS and its components in multivariate logistic regression analysis.

\begin{tabular}{|c|c|c|c|c|c|c|}
\hline Variables & $\begin{array}{c}\text { MetS } \\
\text { OR }(95 \% \mathrm{Cl})\end{array}$ & $\begin{array}{c}\text { Abdominal obesity } \\
\text { OR }(95 \% \mathrm{Cl})\end{array}$ & $\begin{array}{l}\text { Elevated BG } \\
\text { OR }(95 \% \mathrm{Cl})\end{array}$ & $\begin{array}{l}\text { Elevated BP } \\
\text { OR }(95 \% \mathrm{CI})\end{array}$ & $\begin{array}{l}\text { Elevated TG } \\
\text { OR }(95 \% \mathrm{CI})\end{array}$ & $\begin{array}{l}\text { Low HDL-C } \\
\text { OR }(95 \% \mathrm{Cl})\end{array}$ \\
\hline \multicolumn{7}{|l|}{ SES } \\
\hline $\mathrm{T} 1$ & Reference & Reference & Reference & Reference & Reference & Reference \\
\hline $\mathrm{T} 2$ & $0.87(0.66,1.15)$ & $0.83(0.62,1.10)$ & $1.04(0.79,1.37)$ & $0.87(0.69,1.10)$ & $1.05(0.82,1.34)$ & $0.76(0.55,1.05)$ \\
\hline T3 & $0.96(0.70,1.33)$ & $0.79(0.57,1.09)$ & $1.10(0.80,1.51)$ & $0.71(0.54,0.92)^{\star}$ & $1.07(0.81,1.41)$ & $1.09(0.77,1.55)$ \\
\hline \multicolumn{7}{|l|}{ Age } \\
\hline $18-29$ & Reference & Reference & Reference & Reference & Reference & Reference \\
\hline 30-39 & $2.06(1.43,2.97)^{\star}$ & $1.91(1.35,2.71)^{\star}$ & $3.47(2.23,5.40)^{\star}$ & $1.58(1.202,2.08)^{*}$ & $2.24(1.68,2.98)^{\star}$ & $0.98(0.69,1.31)$ \\
\hline $40-49$ & $2.21(1.55,3.17)^{\star}$ & $1.87(1.33,2.62)^{\star}$ & $5.68(3.71,8.71)^{\star}$ & $2.17(1.66,2.83)^{\star}$ & $2.32(1.75,3.07)^{\star}$ & $0.75(0.52,1.07)$ \\
\hline $50-59$ & $5.93(4.09,8.60)^{\star}$ & $5.55(3.86,7.98)^{\star}$ & $12.57(8.16,19.38)^{\star}$ & $4.51(3.37,6.05)^{\star}$ & $2.60(1.92,3.53)^{\star}$ & $0.85(0.58,1.25)$ \\
\hline $60-69$ & $6.24(4.06,9.59)^{\star}$ & $4.30(2.81,6.58)^{\star}$ & $20.17(12.49,32.57)^{\star}$ & $5.88(4.089,8.46)^{\star}$ & $2.06(1.41,2.99)^{\star}$ & $0.72(0.44,1.18)$ \\
\hline $70-$ & $8.74(5.46,13.98)^{\star}$ & $5.31(3.34,8.42)^{\star}$ & $36.18(21.65,60.46)^{\star}$ & $9.37(6.10,14.38)^{*}$ & $2.00(1.31,3.03)^{\star}$ & $0.73(0.42,1.28)$ \\
\hline \multicolumn{7}{|l|}{ Sex } \\
\hline Male & Reference & Reference & Reference & Reference & Reference & Reference \\
\hline Female & $0.48(0.37,0.61)^{\star}$ & $0.43(0.34,0.56)^{\star}$ & $0.78(0.62,0.99)^{\star}$ & $0.46(0.37,0.57)^{\star}$ & $0.76(0.61,0.94)^{*}$ & $0.38(0.28,0.51)^{\star}$ \\
\hline \multicolumn{7}{|l|}{ BMI } \\
\hline Normal & Reference & Reference & Reference & Reference & Reference & Reference \\
\hline Overweight & $4.28(3.19,5.76)^{\star}$ & $6.80(5.26,8.80)^{\star}$ & $1.49(1.16,1.92)^{\star}$ & $2.18(1.77,2.68)^{\star}$ & $2.36(1.89,2.95)^{\star}$ & $3.85(2.72,5.44)^{\star}$ \\
\hline Obesity & $18.26(13.36,24.96)^{\star}$ & $85.50(59.93,121.97)^{\star}$ & $3.59(2.73,4.71)^{\star}$ & $4.83(3.80,6.14)^{\star}$ & $4.24(3.33,5.40)^{\star}$ & $7.08(4.97,10.08)^{\star}$ \\
\hline \multicolumn{7}{|l|}{ Area } \\
\hline Urban & Reference & Reference & Reference & Reference & Reference & Reference \\
\hline Rural & $0.95(0.77,1.19)$ & $1.61(1.28,2.02)^{\star}$ & $0.75(0.60,0.93)^{\star}$ & $1.23(1.02,1.48)^{\star}$ & $0.45(0.37,0.55)^{\star}$ & $1.66(1.30,2.13)^{\star}$ \\
\hline \multicolumn{7}{|l|}{ Smoking } \\
\hline No & Reference & Reference & Reference & Reference & Reference & Reference \\
\hline Yes & $1.31(1.02,1.68)^{\star}$ & $0.99(0.76,1.30)$ & $1.10(0.85,1.42)$ & $0.93(0.74,1.16)$ & $1.42(1.14,1.78)^{\star}$ & $1.35(1.04,1.77)^{*}$ \\
\hline \multicolumn{7}{|l|}{ Salt intake } \\
\hline Mild & Reference & Reference & Reference & Reference & Reference & Reference \\
\hline Moderate & $1.22(0.91,1.66)$ & $1.09(0.80,1.47)$ & $0.89(0.67,1.18)$ & $0.85(0.66,1.09)$ & $1.13(0.88,1.45)$ & $0.96(0.68,1.36)$ \\
\hline Heavy & $1.34(0.93,1.93)$ & $1.03(0.71,1.50)$ & $0.87(0.61,1.23)$ & $1.04(0.76,1.43)$ & $1.51(1.10,2.06)^{\star}$ & $1.13(0.75,1.71)$ \\
\hline \multicolumn{7}{|c|}{ Family history of diabetes } \\
\hline No & Reference & Reference & Reference & Reference & Reference & Reference \\
\hline Yes & $1.37(1.07,1.75)^{\star}$ & $0.98(0.76,1.26)$ & $1.66(1.30,2.11)^{\star}$ & $0.87(0.70,1.07)$ & $1.28(1.03,1.58)^{\star}$ & $1.766(1.36,2.30)^{\star}$ \\
\hline
\end{tabular}

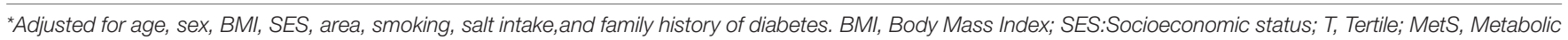
Syndrome; BG, blood Glucose; BP, Blood Pressure; TG, triglycerides; HDL-C, High-Density Lipoprotein-Cholesterol. *Statistically significant.

increased significantly in participants from overweight to obesity. Participants living in rural areas had a lower risk of developing elevated BG and elevated TG but have an increased risk of abdominal obesity, elevated BP, and low HDL-C compared with people living in urban areas. Our data also suggested that heavy salt intake, smoking, and diabetes history were associated with the prevalence of cardio-metabolic parameters.

Adjusted ORs for MetS and its components between SES in males and females are presented in Table 4. It is observed that females with higher SES had significantly lower ORs in 
TABLE 4 | Adjusted odds ratios in SES for MetS and its components between risk factors in males or females.

\begin{tabular}{|c|c|c|c|c|c|c|}
\hline Variables & $\begin{array}{c}\text { MetS } \\
\text { OR }(95 \% \mathrm{CI})\end{array}$ & $\begin{array}{c}\text { Abdominal obesity } \\
\text { OR }(95 \% \mathrm{Cl})\end{array}$ & $\begin{array}{l}\text { Elevated BG } \\
\text { OR (95\% Cl) }\end{array}$ & $\begin{array}{l}\text { Elevated BP } \\
\text { OR (95\% Cl) }\end{array}$ & $\begin{array}{l}\text { Elevated TG } \\
\text { OR }(95 \% \mathrm{CI})\end{array}$ & $\begin{array}{l}\text { Low HDL-C } \\
\text { OR (95\% Cl) }\end{array}$ \\
\hline \multicolumn{7}{|c|}{ SES in males } \\
\hline T1 & Reference & Reference & Reference & Reference & Reference & Reference \\
\hline $\mathrm{T} 2$ & $1.04(0.71,1.51)$ & $0.93(0.62,1.39)$ & $1.28(0.89,1.85)$ & $0.90(0.64,1.27)$ & $1.06(0.75,1.51)$ & $0.67(0.43,1.04)$ \\
\hline T3 & $1.19(0.79,1.80)$ & $0.85(0.54,1.33)$ & $0.99(0.67,1.47)$ & $0.76(0.53,1.10)$ & $1.39(0.95,2.04)$ & $1.07(0.67,1.69)$ \\
\hline \multicolumn{7}{|c|}{ SES in females } \\
\hline T1 & Reference & Reference & Reference & Reference & Reference & Reference \\
\hline $\mathrm{T} 2$ & $0.87(0.59,1.28)$ & $0.77(0.51,1.17)$ & $0.78(0.57,1.08)$ & $0.84(0.60,1.18)$ & $1.08(0.76,1.53)$ & $0.90(0.65,1.25)$ \\
\hline T3 & $0.72(0.45,1.15)$ & $0.80(0.48,1.33)$ & $0.81(0.57,1.15)$ & $0.65(0.43,0.97)^{\star}$ & $0.73(0.48,1.10)$ & $1.15(0.79,1.66)$ \\
\hline
\end{tabular}

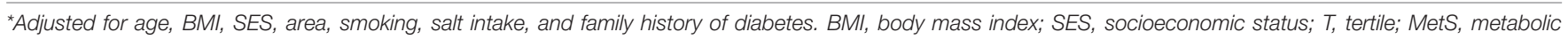
syndrome; BG, blood glucose; BP, blood pressure; TG, triglycerides; HDL-C, high-density lipoprotein-cholesterol. *Statistically significant.

TABLE 5 | Adjusted odds ratios in SES for MetS and its components between risk factors in urban or rural area.*

\begin{tabular}{|c|c|c|c|c|c|c|}
\hline Variables & $\begin{array}{c}\text { MetS } \\
\text { OR }(95 \% \mathrm{Cl})\end{array}$ & $\begin{array}{c}\text { Abdominal obesity } \\
\text { OR }(95 \% \mathrm{Cl})\end{array}$ & $\begin{array}{l}\text { Elevated BG } \\
\text { OR }(95 \% \mathrm{Cl})\end{array}$ & $\begin{array}{l}\text { Elevated BP } \\
\text { OR }(95 \% \mathrm{Cl})\end{array}$ & $\begin{array}{l}\text { Elevated TG } \\
\text { OR }(95 \% \mathrm{Cl})\end{array}$ & $\begin{array}{l}\text { Low HDL-C } \\
\text { OR (95\% Cl) }\end{array}$ \\
\hline \multicolumn{7}{|c|}{ SES in urban area } \\
\hline T1 & Reference & Reference & Reference & Reference & Reference & Reference \\
\hline T2 & $0.94(0.61,1.45)$ & $0.68(0.44,1.04)$ & $1.33(0.88,2.01)$ & $0.792(0.543,1.153)$ & $1.21(0.85,1.73)$ & $0.96(0.56,1.64)$ \\
\hline T3 & $1.18(0.75,1.85)$ & $0.76(0.49,1.19)$ & $1.67(1.08,2.59)^{\star}$ & $0.78(0.532,1.144)$ & $1.12(0.78,1.62)$ & $1.31(0.77,2.23)$ \\
\hline \multicolumn{7}{|c|}{ SES in rural area } \\
\hline T1 & Reference & Reference & Reference & Reference & Reference & Reference \\
\hline T2 & $0.83(0.57,1.21)$ & $0.94(0.63,1.40)$ & $0.85(0.58,1.25)$ & $0.99(0.72,1.35)$ & $0.90(0.63,1.28)$ & $0.66(0.43,1.01)$ \\
\hline T3 & $0.74(0.45,1.21)$ & $0.78(0.47,1.31)$ & $0.61(0.35,1.05)$ & $0.56(0.38,0.84)^{\star}$ & $1.02(0.65,1.58)$ & $1.01(0.62,1.66)$ \\
\hline
\end{tabular}

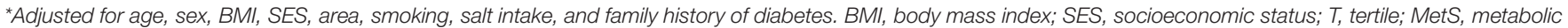
syndrome; BG, blood glucose; BP, blood pressure; TG, triglycerides; HDL-C, high-density lipoprotein-cholesterol. *Statistically significant.

developing elevated BP (OR:0.65, 95\% CI:0.43-0.97). Adjusted ORs for MetS and its components between SES in urban or rural areas are presented in Table 5. The data showed that people with higher SES had a high risk of developing elevated BG (OR: 1.67, 95\% CI: 1.08-2.59) in urban areas and low risk of having an elevated BP (OR:0.56, 95\% CI:0.38-0.84) in rural areas.

Unadjusted and age-sex-adjusted odds ratios for MetS and its components among risk factors by sensitivity analysis are presented in Supplementary Tables 2, 3.

\section{DISCUSSION}

Metabolic syndrome (MetS) has become a major threat to public health worldwide (16). If left untreated, patients with MetS are disposed to a series of chronic diseases such as diabetes, cardiovascular disease, and cognitive dysfunction, and have increased all-cause and cardiovascular death $(17,18)$.

Among all diagnosing guidelines, Adult Treatment Panel III (ATP III- 2002) (19), International Diabetes Federation criteria (IDF-2004) (20), and Chinese Diabetes Society (CDS-2004) (21) are three frequently used guidelines in clinical practice and published articles. However, the diagnostic results are largely affected by which one of these three guidelines are applied in the analysis (22). Given that the Chinese have experienced rapid socioeconomic transitions during these years, adopting the latest CDS criteria (CDS-2017) might increase the accuracy of describing the prevalence of MetS in Chinese adults (15).

The prevalence of MetS has been increasing in recent years (16), especially in China, which faced great social and economic transitions in the last decade. Identifying populations at risk would contribute to more effective screening and prevention. Generally, the prevalence of MetS varies in different regions in China. It was reported that the adjusted prevalence of MetS across China was $11 \%$ in 2010 by 2004 CDS criteria (23). The prevalence of MetS was $16.7 \%$ in adult Hong Kong Chinese in 2005 by NCEP ATP III (24). In highly urbanized Beijing, MetS prevalence was $14.05 \%$ for males and $28.55 \%$ for females according to NCEP ATP III in 2007 (25). In our study, the weighted prevalence of MetS was $26.8 \%$ in Hebei, and $18.4 \%$ for females and $35.4 \%$ for males. Possible origins may be attributed to inequality in education, income, and occupation, and their associations with health between developed and developing areas in China, which has been discussed in many bodies of literature $(26,27)$.

A composite SES score was then calculated to better understand the overall condition of SES (28). Patients with lower SES condition had increased prevalence of developing cardio-metabolic disorders, such as MetS and abdominal obesity (Table 2). Our results were consistent with earlier studies, which demonstrated that better SES is associated with lower rates of specific diseases such as coronary disease, diabetes, cognitive impairment, stroke, cancer, and arthritis $(29,30)$. Higher SES 
is generally associated with better education, income, medical services and other social benefits that provide positive effects on health (31). However, economic stress and social vulnerability are risk factors for various chronic disorders, particularly cardiovascular diseases (17). People with lower SES are generally more stressed, which often leads to restricted opportunities for good health services (32).

Differences in prevalence of MetS between males (35.4\%) and females $(18.4 \%)$ were significant $(p<0.01)$. Consistent with a previous study, our data suggested that females were less likely to develop MetS and other related cardio-metabolic risk parameters (Table 3) (33). After multivariate adjustments, the ORs for MetS increased with higher SES levels in males. As for females, inverse associations were shown between SES and MetS. Lower SES was associated with higher risk of MetS among females (Table 4). However, the associations between them were not statistically significant, which might be attributed to lack of sufficient sample size. This was consistent with other findings in Korea (34) and China (25). Another possible explanation may contribute to the gender differences. Males with better SES may spend more time sitting in the office, have little time to exercise, frequently consume high-fat foods, and suffer from work-related mental health problems (35).

The analysis was then stratified by living area (Table 5). The ORs for elevated BG increased with higher SES levels in urban areas and for elevated BP decreased with higher SES levels in rural areas. The possible mechanism for different regional impacts of SES on MetS in urbanization may through unhealthy behaviors, such as decreased physical activity, excessive intake of animal fats and salts, and low intake of fruits and vegetables in urban areas (36).

Moreover, a relationship was observed between prevalence of MetS and age in both males and females, which is similar to other studies $(37,38)$. The increased prevalence of MetS with age can be attributed to similar age-related trends in all components of MetS $(39,40)$. The most common cardio-metabolic risk factors in Hebei province we identified in this study were elevated BP (45.6\%) and abdominal obesity (42.9\%). These data raised a red flag to public health that urgent measures need to be taken to prevent elevated BP-related and obesity-related cardiometabolic disorders in high-risk populations of Hebei province. Additionally, smoking and family history of diabetes were also independent risk factors for MetS and its components, as seen in previous studies (41).

Previous studies have shown that the link between SES and MetS was significant and positive (28). However, our results found that the association between them was not statistically significant (Table 3), which was consistent with other studies $(42,43)$. Several explanations are possible. First, despite several diagnostic criteria of MetS such as ATP III criteria, IDF criteria, and CDS criteria, worldwide-accepted criteria do not exist. The CDS-2017 criteria were used in our study for better applicability in Chinese populations. Second, there is no unique definition for SES. It can be social, economic, or psychosocial. An analysis per type of status could show different links with MetS in terms of significance, sign, and magnitude. Third, our study focused mainly on age, sex, and living area. Other behavioral risk factors such as alcohol use, dietary quality, and physical activity were not discussed. Fourth, the null association between SES and MetS may be due to sample size issues. Our study only included data from a region in north China. The conclusion of this study should be further examined in prospective studies in the future.

In summary, the prevalence of MetS and cardio-metabolic risk factors is partially conditioned by individual SES status, which should be taken into account by healthcare professionals when making preventive strategies to reduce health inequality in society. Overall, our results supported the idea that there was a definite association between SES and prevalence of cardiometabolic risk factors in a developing area in China.

\section{CONCLUSION}

This was the first cross-sectional study to examine the associations between SES and MetS, as well as its cardiometabolic components, in north China, Hebei province. Our data suggested that better SES conditions were associated with lower prevalence of MetS and abdominal obesity. Lower SES condition, male gender, older age, obesity, smoking, and family history of diabetes were associated with higher risk of developing cardio-metabolic disorders. This should be the target group for possible early lifestyle intervention to reduce the occurrence of cardio-metabolic disorders in less developed areas in China.

\section{DATA AVAILABILITY STATEMENT}

The original contributions presented in the study are included in the article/Supplementary Material, further inquiries can be directed to the corresponding author.

\section{ETHICS STATEMENT}

The studies involving human participants were reviewed and approved by Medical Ethics Committee of The Second Hospital of Hebei Medical University. The patients/participants provided their written informed consent to participate in this study.

\section{AUTHOR CONTRIBUTIONS}

$\mathrm{ZH}$ analyzed the data, drafted, reviewed, and edited the manuscript, and contributed to the discussion. LZ and MW conducted, designed, and supervised the study, reviewed and edited the manuscript, and contributed to the discussion. QZ, JL, ZL, LY, and YZ complemented the study, reviewed the manuscript and contributed to the discussion. All authors read and approved the final version of the manuscript.

\section{FUNDING}

This study was supported by the Research Fund for Public Welfare from the National Health and Family Planning Commission of China (Grant No: 201402005). 


\section{ACKNOWLEDGMENTS}

We thank all the participants of this study and the local medical care professionals for their valuable contributions.

\section{REFERENCES}

1. World Health Organization. Global Status Report on Noncommunicable Diseases 2010. Geneva: World Health Organization (2011).

2. Wagner $\mathrm{KH}$, Brath $\mathrm{H}$. A global view on the development of noncommunicable diseases. Prev Med. (2012) 54(Suppl.):S38-41. doi: 10.1016/j.ypmed.2011.11. 012

3. O'Donovan MR, Gapp C, Stein C. Burden of disease studies in the WHO European Region- a mapping exercise. Eur J Public Health. (2018) 28:773-8. doi: 10.1093/eurpub/cky060

4. Wilson PW, D'Agostino RB, Parise H, Sullivan L, Meigs JB. Metabolic syndrome as a precursor of cardiovascular disease and type 2 diabetes mellitus. Circulation. (2005) 112:3066-72. doi: 10.1161/CIRCULATIONAHA. 105.539528

5. Chen WW, Gao RL, Liu LS, Zhu ML, Wang W, Wang YJ, et al. China cardiovascular diseases report 2015: a summary. J Geriatr Cardiol. (2017) 14:1-10. doi: 10.11909/j.issn.1671-5411.2017.01.012

6. Kastorini CM, Panagiotakos DB, Georgousopoulou EN, Laskaris A, Skourlis $\mathrm{N}$, Zana A, et al. Metabolic syndrome and 10-year cardiovascular disease incidence: the ATTICA study. Nutr Metab Cardiovasc Dis. (2016) 26:223-31. doi: 10.1016/j.numecd.2015.12.010

7. Martínez-Larrad MT, Corbatón-Anchuelo A, Fernández-Pérez C, LazcanoRedondo Y, Escobar-Jiménez F, Serrano-Ríos M. Metabolic syndrome, glucose tolerance categories and the cardiovascular risk in Spanish population. Diabetes Res Clin Pract. (2016) 114:23-31. doi: 10.1016/j.diabres.2016.02.003

8. Wang LS, Zhang B, Wang HJ, Guo CL, Zhang YP, Zhang JG, et al. Analysis on cardio-metabolic related risk factors in farmers of 15 provinces in China. Zhonghua Liu Xing Bing Xue Za Zhi. (2018) 39:1239-43. doi: 10.3760/cma.j. issn.0254-6450.2018.09.018

9. Zhu S, St-Onge MP, Heshka S, Heymsfield SB. Lifestyle behaviors associated with lower risk of having the metabolic syndrome. Metabolism. (2004) 53:1503-11. doi: 10.1016/j.metabol.2004.04.017

10. Clark AM, DesMeules M, Luo W, Duncan AS, Wielgosz A. Socioeconomic status and cardiovascular disease: risks and implications for care. Nat Rev Cardiol. (2009) 6:712-22. doi: 10.1038/nrcardio.2009.163

11. Lan Y, Mai ZL, Zhou SY, Liu Y, Li SJ, Zhao ZJ, et al. Prevalence of metabolic syndrome in China: an up-dated cross-sectional study. PLoS One. (2018) 13:196-212. doi: 10.1371/journal.pone.0196012

12. Lao XQ, Zhang YH, Wong MCS, Xu YJ, Xu HF, Nie SP, et al. The prevalence of metabolic syndrome and cardiovascular risk factors in adults in southern China. BMC Public Health. (2012) 12:64. doi: 10.1186/1471-2458-12-64

13. Wu HF, Tam T, Jin L, Lao XQ, Chung RY, Su XF, et al. Age, gender, and socioeconomic gradients in metabolic syndrome: biomarker evidence from a large sample in Taiwan, 2005-2013. Ann Epidemiol. (2017) 27:315-22. doi: 10.1016/j.annepidem.2017.04.003

14. National Bureau of Statistics of China . Tabulation on the 2010 PopulationCensus of the People's Republic of China. (2010). Available online at: http://www.stats.gov.cn/tjsj/pcsj/rkpc/6rp/indexch.htm (accessed February 15, 2021).

15. Tong YZ, Tong NW, Teng WP, Mu YM, Zhao JJ, Shan ZY. Consensus on the prevention of type 2 diabetes in Chinese adults. Chin Med J (Engl). (2017) 130:600-6. doi: 10.4103/0366-6999.200532

16. Shin D, Kongpakpaisarn K, Bohra C. Trends in the prevalence of metabolic syndrome and its components in the United States 2007-2014. Int J Cardiol. (2018) 259:216-9. doi: 10.1016/j.ijcard.2018.01.139

17. Havranek EP, Mujahid MS, Barr DA, Blair IV, Cohen MS, Cruz-Flores S, et al. Social determinants of risk and outcomes for cardiovascular disease: a scientifific statement from the American heart association. Circulation. (2015) 132:873-98. doi: 10.1161/CIR.0000000000000228

\section{SUPPLEMENTARY MATERIAL}

The Supplementary Material for this article can be found online at: https://www.frontiersin.org/articles/10.3389/fcvm. 2022.698895/full\#supplementary-material

18. Sumner AD, Sardi GL, Reed JF. Components of the metabolic syndrome differ between young and old adults in the US population. J Clin Hyperten (Greenwich). (2012) 14:502-6. doi: 10.1111/j.1751-7176.2012.00647.x

19. National Cholesterol Education Program (NCEP) Expert Panel on Detection, Evaluation, and Treatment of High Blood Cholesterol in Adults (Adult Treatment Panel III). Third report of the national cholesterol education program (NCEP) expert panel on detection, evaluation, and treatment of high blood cholesterol in adults (Adult Treatment Panel III) final report. Circulation. (2002) 106:3143-421.

20. Ford ES. Prevalence of the metabolic syndrome defined by the International Diabetes Federation among adults in the U.S. Diabetes Care. (2005) 28:2745-9. doi: $10.2337 /$ diacare.28.11.2745

21. Chinese Diabetes Society. Recommendations provided by Chinese diabetes society on metabolic syndrome. Chin J Diabetes. (2004) 12:156-61.

22. Wu J, Yan WH, Qiu L, Chen XQ, Guo XZ, Wu W, et al. High prevalence of coexisting prehypertension and prediabetes among healthy adults in northern and northeastern China. BMC Public Health. (2011) 11:794-801. doi: 10.1186/ 1471-2458-11-794

23. He YN, Zhao WH, Zhao LY, Lu DM, Zhang J, Yang XG, et al. Prevalence of metabolic syndrome in Chinese adults in 2010-2012. Zhonghua Liu Xing Bing Xue Za Zhi. (2017) 38:212-5. doi: 10.3760/cma.j.issn.0254-6450.2017. 02.015

24. Thomas GN, Ho SY, Janus ED, Lam KSL, Hedley AJ, Lam TH, et al. The US national cholesterol education programme adult treatment panel III (NCEP ATP III) prevalence of the metabolic syndrome in a Chinese population: the Hong Kong cardiovascular risk factor study. Diabetes Res Clin Pract. (2005) 67:251-7. doi: 10.1016/j.diabres.2004. 07.022

25. Zhan YQ, Yu JM, Chen RQ, Gao JL, Ding RJ, Fu YY, et al. Socioeconomic status and metabolic syndrome in the general population of China: a crosssectional study. BMC Public Health. (2012) 12:921. doi: 10.1186/1471-245812-921

26. Backlund E, Rowe G, Lynch J, Wolfson MC, Kaplan GA, Sorlie PD. Income inequality and mortality: a multilevel prospective study of 521248 individuals in 50 US states. Int J Epidemiol. (2007) 36:590-6. doi: 10.1093/ije/ dym012

27. Dowd JB, Albright J, Raghunathan TE, Schoeni RF, Leclere F, Kaplan GA. Deeper and wider: income and mortality in the USA over three decades. Int J Epidemiol. (2011) 40:183-8. doi: 10.1093/ije/dyq189

28. Blanquet M, Legrand A, Pélissier A, Mourgues C. Socio-economics status and metabolic syndrome: a meta-analysis. Diabetes Metab Syndr. (2019) 13:180512. doi: 10.1016/j.dsx.2019.04.003

29. Kawada T. Socioeconomic status and cardiovascular disease. Int J Cardiol. (2019) 274:378. doi: 10.1016/j.ijcard.2018.07.034

30. Miguel AF, Bárbara NR, Marina ÁV, Meritxell VS, Belén FP, Teodoro DS, et al. Impact of individual and neighborhood dimensions of socioeconomic status on the prevalence of mild cognitive impairment over seven-year follow-up. Aging Ment Health. (2020) 2:1-10. doi: 10.1080/13607863.2020.172 5803

31. Rosso AL, Flatt JD, Carlson MC, Lovasi GS, Rosano C, Brown AF, et al. Neighborhood socioeconomic status and cognitive function in late life. Am J Epidemiol. (2016) 183:1088-97. doi: 10.1093/aje/kwv337

32. Glymour MM, Manly JJ. Lifecourse social conditions and racial and ethnic patterns of cognitive aging. Neuropsycholo Rev. (2008) 18:223-54. doi: 10 1007/s11065-008-9064-Z

33. Guo HJ, Nian X, Liang YF, Wang XL, Li KL, Wang Q, et al. The prevalence and risk factors of metabolic syndrome in Chinese population based on the multicenter cross-sectional survey. Chin J Dis Control Prevent. (2019) 23:796-801 
34. Park MJ, Yun KE, Lee GE, Cho HJ, Park HS. A cross-sectional study of socioeconomic status and the metabolic syndrome in Korean adults. Ann Epidemiol. (2007) 17:320-6. doi: 10.1016/j.annepidem.2006.10.007

35. Li YR, Zhao LY, Yu DM, Wang ZH, Ding GQ. Metabolic syndrome prevalence and its risk factors among adults in China: A nationally representative crosssectional study. PLoS One. (2018) 13:e0199293. doi: 10.1371/journal.pone. 0199293

36. Xi B, He D, Hu YH, Zhou DH. Prevalence of metabolic syndrome and its influencing factors among the Chinese adults: the China Health and Nutrition Survey in 2009. Prev Med. (2013) 57:867-71. doi: 10.1016/j.ypmed.2013.09.023

37. Park YH, Shin JA, Han K, Yim HW, Lee WC, Park YM. Gender difference in the association of metabolic syndrome and its components with agerelated cataract: the Korea National Health and Nutrition Examination Survey 2008-2010. PLoS One. (2014) 9:850-68. doi: 10.1371/journal.pone.0085068

38. Escobedo J, Schargrodsky H, Champagne B, Silva H, Boissonnet CP, Vinueza $\mathrm{R}$, et al. Prevalence of the metabolic syndrome in Latin America and its association with sub-clinical carotid atherosclerosis: the CARMELA cross sectional study. Cardiovasc Diabetol. (2009) 8:52. doi: 10.1186/1475-2840-852

39. Lao XQ, Ma WJ, Sobko T, Zhang YH, Xu YJ, Xu XJ, et al. Dramatic escalation in metabolic syndrome and cardiovascular risk in a Chinese population experiencing rapid economic development. BMC Public Health. (2014) 14:983. doi: 10.1186/1471-2458-14-983

40. Zhao Y, Jin J, Liu XY, Xu HX, Yang JJ, Zhang YH. Prevalence of the metabolic syndrome among rural original adults in NingXia, China. BMC Public Health. (2010) 10:140. doi: 10.1186/1471-2458-10-140

41. Riediger ND, Clara I. Prevalence of metabolic syndrome in the Canadian adult population. Can Med Assoc J. (2011) 183:e1127-34. doi: 10.1503/cmaj.190063
42. Langenberg C, Kuh D, Wadsworth MEJ, Brunner E, Hardy R. Social circumstances and education: life course origins of social inequalities in metabolic risk in a prospective national birth cohort. Am J Public Health. (2006) 96:2216-21. doi: 10.2105/AJPH.2004.04 9429

43. Kyoung IC, Bo HK, Hyung GJ, Jae SJ, Yong HP. Gender-specific associations between socioeconomic status and psychological factors and metabolic syndrome in the korean population: findings from the 2013 korean national health and nutrition examination survey. Biomed Res Int. (2016) 25:3973197. doi: $10.1155 / 2016 / 3973197$

Conflict of Interest: The authors declare that the research was conducted in the absence of any commercial or financial relationships that could be construed as a potential conflict of interest.

Publisher's Note: All claims expressed in this article are solely those of the authors and do not necessarily represent those of their affiliated organizations, or those of the publisher, the editors and the reviewers. Any product that may be evaluated in this article, or claim that may be made by its manufacturer, is not guaranteed or endorsed by the publisher.

Copyright (c) 2022 Hao, Wang, Zhu, Li, Liu, Yuan, Zhang and Zhang. This is an open-access article distributed under the terms of the Creative Commons Attribution License (CC BY). The use, distribution or reproduction in other forums is permitted, provided the original author(s) and the copyright owner(s) are credited and that the original publication in this journal is cited, in accordance with accepted academic practice. No use, distribution or reproduction is permitted which does not comply with these terms. 